\title{
Clinical Teaching of Nurses in Southern Chile Hospitals: Practical Wisdom and Intersubjectivity
}

Juan Mansilla Sepúlveda*, Alejandra Ricouz Moya and Claudia Huaiquián Billeke

University Catholic of Temuco, Región de la Araucanía, Chile

*Corresponding author: JG Mansilla, Facultad de Educación, University Catholic of Temuco, Campus San Juan Pablo II, Rudecindo Ortega 02950, Temuco, Región de la Araucanía, Chile, Tel: +56 452 205640; E-mail: jmansilla@uct.cl

Received date: August 30, 2017; Accepted date: September 16, 2017; Published date: September 25, 2017

Copyright: (c) 2017 Sepúlveda JM, et al. This is an open-access article distributed under the terms of the Creative Commons Attribution License, which permits unrestricted use, distribution, and reproduction in any medium, provided the original author and source are credited

\author{
Abstract \\ Purpose: The purpose of this study was to describe the significance of the intersubjectivity that is present in \\ clinical educators in selected hospitals in La Araucanía, Los Lagos and Los Ríos regions.
}

Methods: A qualitative, exploratory, contextual and descriptive design was used and this approach was regarded as the most appropriate for this study. The population of this study consisted of thirty clinical educator nurses from three hospitals in southern Chile to the clinical teaching role.

Data collection: Data was collected by means of focus group discussion interviews during which participants were able to describe their experiences of the clinical placement in the real life setting and the support received from the professional nurses. Data were collected until data saturation was reached.

Data analysis: The researcher used the process of bracketing and remained neutral, setting aside previous knowledge and beliefs about the phenomenon under investigation. The researcher listened to the audiotapes used for data collection several times until the researcher completely satisfied with the interpretation of the verbatim data. The codes established are as follows: otherness valuation, motivation and learning by mistake, support need, professional experience valuation, value settlement, practical and theoretical articulation, comprehension and otherness, ethics of the host, pedagogical model, ethical-moral responsibility, subjectivity formation, face-to-face interaction and support need.

Ethical consideration: The research is based on the Singapore Declaration and has the informed consent of the nurses interviewed.

Keywords: Nursing faculty practice; Nursing faculty; Nursing education; Students; Nursing; Clinical clerkship; Intersubjectivity

\section{Introduction}

The clinical practices in hospitals constitute an essential professional place in the training of nurses, which is complementary to the training that takes place in university classrooms. In this circumstance the students mobilize the specific competences to develop their profession, and in this way to consolidate competences and disciplinary codes for the undertaking of the human being care [1]. In this context, the university educator and the teaching assistant in nursing formative articulation is the optimal intersection between theory and practice, which facilitates the student's integral development through a reflexive, scientific and authentic thinking, considering the local reality where the student has to work professionally [2]. This integration is a complex challenge, as the student implies more work burnout and a double concern for the clinical nurse "the patient and the student in practice." Furthermore, the role of nurses' formative modeling is affected by their permanent rotation in health care services. In this context, a critical dimension in this process corresponds to the actual pedagogical time destined for the teaching, which is not considered realistically in the curricular programs of the universities [3].
Currently, the professional role of the nurse is legally legitimized by Article 113 of the Chilean Health Code, to which the Sanitary Authority Act of 2004 is added [4]. In addition to this, the enactment of the General Technical Regulation which operationalizes the nursing care management in public hospitals is added, giving it a great responsibility and numerous functions and attributions that strengthen and deepen the professional role of nursing [5]. The field of clinical teaching, as part of the training process, gives the student opportunities for reflection on professional action and a critical view of the dynamics of existing relationships in the environment, which favor the theoretical and practical integration, provide the development of new knowledge, and influence the attitudinal, conceptual and procedural formation [6]. Therefore, in clinical practice, the student is confronted with his/her new formative reality, starting an experiential learning process in which he/she is trained from the practical wisdom and the technical-instrumental nature of the process to integrate himself/herself as a beginner professional [7].

Nursing is responsible for the care itself, through the patient's care, reception and well-being, and the coordination and intersection with other clinical fields to provide health care. Nursing care can be understood as a communicative and intersubjective act that requires specific knowledge and understanding of the context in which the people live, work and get sick [8]. 
In the same vein, the practice of teaching is still exercised intuitively. The traditional paradigm from which it is argued that a professional for the mere fact of being one - can teach his/her discipline, still remains to a greater extent in various professional fields. However, the empirical evidence demonstrates the lack of didactic knowledge of the content to deal with teaching and clinical tutoring with bases and tools that facilitate the deep learning and students' learning [9]. The "teaching" attribute occupies an important place for the total of participants, "interpreted as the fulfillment of the competences related to knowledge (conceptual knowledge), knowing how to do something (procedural knowledge) and knowing how to be (values)" [10].

The importance of the clinical educator in the student's formation is visualized in the multiple functions that he/she develops, from the support delivery to the modeling; thus, the intersubjective relationship between the teacher and the student are important [11].

All these variables converge to determine that nursing has different roles within the clinical teaching: a) task performance, b) appropriate care delivery to the patient at the required time, c) appropriate care delivery to the patient focused on the achievement of individual outcomes for the patient, and d) collaboration in the delivery of that appropriate care [6-12].

At present, the teaching-assistance relationship of health facilities, such as the Base de Valdivia Hospital and the Hernán Henríquez Aravena de Temuco Regional Hospital is regulated by the General Administrative Technical Norm $\mathrm{N}^{\circ} 18$ from MINSAL (Chilean Health Ministry), updated in 2012, in which the allocation and use of clinical fields' criteria are established [13]. It is possible to say that the norm does not contemplate preparation and improvement as teaching requirements that the professionals must have in order to perform functions such as demonstration, accompaniment and supervision of students.

In light of this situation, practice environments are complex, and the amount of data and information nurses handle is ample, as they must assimilate a great deal of information about each person and decide what to do. The theory allows them to organize and understand what happens in life to critically analyze the patient's situations, make clinical decisions, plan the patient's care, propose appropriate nursing interventions, predict patient outcomes and evaluate the effectiveness of care [14].

In the field of health, many aspects related to health practices can be studied under the hermeneutical approach, since this is a field that sustains constant interpretation and knowledge synthesis tasks, providing conditions to recognize different interests and contrariness that are present in a given interaction, and creating new possibilities for a new meaning ad reconstruction [15].

The clinical pedagogical practice is not only another discipline about man, which is parallel to the others, but also it is a kind of social knowledge that re-elaborates and reconstructs the senses produced by a particular historical and cultural horizon. Any health related action has an instrumental meaning and a technical basis derived from the knowledge setting-up in the health area [16].

The pedagogy of the otherness appears as an epistemological possibility for nursing professionals, in which the main action axis is developed through the attention to people; the broad system of theories, in which the science of nursing is based upon, is applied in its instrumentalization. It is about a deliberate approach to problem solving that requires cognitive, technical and interpersonal skills and it is aimed at meeting the patient, the family system and the community needs [17].

It is relevant that the nursing professionals have an orientation for daily situations; a practical orientation, not just a technical one, in order to deal with the process related to health attendance. That process is not natural; it is complex and it must be rebuilt all the time; thus, the integration among the technical success, the practical success and the practical wisdom appreciation is enriching. This is obtained from systematic practice in the world of everyday life. Practical wisdom has a conceivable character, that is, it deals with eventuality, with the doubt, with human events and experiences; it does not deal with perennial, causal and universal aspects. It is not a type of knowledge that produces objects, artifacts or instruments. It is a noncumulative type of knowledge; it can emerge from experiences, from common or divergent interests, from tensions and possibilities of intersubjective relations [16-18].

For the development of professional competences, the students require support, supervision and teaching to facilitate their learning outcomes achievement during their clinical placements [6]. The professional process formation is considered as a teacher-learner relationship, in which both teach and learn enriching each other. This formative act is based on the experiences of each one, so that the learners stop to be oppressed and advance towards their own formation self-regulation [19]. Initially, there are insecurities in the handling of patients, the first intersubjective experiences with death are experienced, and learning is done through the observation of peers and other professionals. The experience that comes out of the practical wisdom finally constitutes the professional being [20]. The intersubjective encounter is the central axis of holistic care, and in order to participate in the cure of the patient, the nurse should address the patient with an open, sincere and meaningful dialogue [21].

\section{Purpose of the Study}

The purpose of the study was to explore and describe the value that intersubjectivity acquires from the practical wisdom of the nursing clinical educator who works in public hospitals in Los Lagos, Los Ríos and La Araucanía regions in Chile.

\section{Research Objectives}

- To explore the value that intersubjectivity acquires and the practical wisdom of the nursing clinical educator who works in public hospitals in the Los Lagos, Los Ríos and La Araucanía regions.

- To describe the value that intersubjectivity acquires and the practical wisdom of the nursing clinical educator who works in public hospitals in the Los Lagos, Los Ríos and La Araucanía regions.

\section{Significance of the Study}

\section{Significance to the learners, nurse educators and professional nurses}

The study results can contribute to improving the initial professional training of nurses who are responsible for the final internships at the universities. Likewise, it allows assuring the training quality through a balance between technical (objective) knowledge and attitudinal (subjective) knowledge, which will contribute competent nurses with a 
focus on the human person, as a value in himself/herself, to society. The fields involved: training colleges/universities and hospitals can help each other to correct problems arising from clinical teaching practices as more research of this nature develops.

\section{Significance of the research}

The study results could contribute to the research in the area of the clinical teaching of nurses, especially in the final phase of the training processes. This study also highlights the profession intersubjective dimension, which in many circumstances seems to be subordinated to the technical-instrumental rationality.

\section{Research Methodology and Research Design}

The research is qualitative, descriptive, oriented by the theoreticalmethodological approach of the tradition of the constructionist grounded theory and with dense descriptive scope. Qualitative methods allow the capture and reconstruction of the performers' meaning from their own points of view [22]. At the same time, through a hermeneutical approach the meanings unveiled by the professionals are interpreted, in order to obtain a deep understanding of the phenomenon, like in this case, the intersubjective relations and the practical wisdom of the clinical teaching of nurses [23].

\section{Research setting}

The study was carried out in the sample hospitals in the cities of Temuco, Valdivia and Osorno, where students are assigned to be supervised by nurse educators.

\section{Population}

According to Burn and Grove [8]; Polit and Beck [9] the population refers to the entire group of people or objects that were of interest to the researcher and which were constituted as units of analysis. The study included 14 nursing professionals from the Base de Valdivia Hospital, 8 from the San José de Osorno Hospital and 8 from the Hernán Henríquez Aravena de Temuco Hospital until achieving saturation of meanings regarding the experience of the clinical teaching role. Therefore, a total of 30 subjects participated in the study. The inclusion criteria were as it follows: a) five or more years of work experience; b) clinical teaching experience of two or more years, as a nurse guide, with nursing students in hospital internship admission period; c) nurse working in hospitalized adult-children services, emergency care and/or ambulatory patients' service; and d) day shift or shift system.

\section{Data collection}

Non-structured interviews, focus groups and field notes were used from observations. Non-structured interviews and focus groups lasted approximately $60 \mathrm{~min}$ and field notes were developed in the context of student practices during their internship period with the presence of the clinical educator. These instruments allow the development of an effective research for the collection of information, for the freedom and flexibility for the decision making during its development, promoting the construction of a holistic and comprehensive knowledge of the reality [24]. All of the above has the aim of unveiling the intersubjective relationships that arise from the practical wisdom that is present in the practice process of students' internships.

\section{Ethical Considerations}

\section{Protecting the rights of the participants}

The researcher avoided discrimination against the Bridging course learners on the basis of sex, race, ethnicity or other factors that were deemed to jeopardise the trustworthiness of the study results [25]. Both individual and societal benefits that are directly related to participation in this research.

\section{Beneficence}

According to Polit and Beck beneficence is the most fundamental principle in research. To adhere to this principle, the well-being (physical, emotional, social of financial) of the respondent must be protected from discomfort and harm [26]. In this study the researcher did not harm and refrain from exploiting participants, and promoted both individual and societal benefits that are directly related to participation in this research.

\section{Right to be informed}

The participants have the right to know what the research entails, how it will influence them, the risks and the benefits and that they may refuse to participate in the study should they choose to do so [27].

\section{Justice}

The principle of justice means that participants need to be treated fairly [28]. The researcher respected the rights of the learners to privacy and the right to fair treatment in the context of research participation [25-28].

\section{Data Analysis}

For the reduction and analysis of qualitative data, once the interviews were made and recorded, they were transcribed in word format in a textual way, which allowed discovering emerging categories in relation to the intersubjective relations of clinical teaching practices of nursing professionals. Recorded field notes were also considered as part of the preliminary information for the analysis [29]. Atlas-ti 8.0 software was used for the coding and theoretical categorization of the data, since it allows the processing of information in a more expeditiously. We established categories and subcategories represented in conceptual networks, which were explained in the analysis of the results, this way facilitating the gathering of the open categories, and allowing the researcher to visualize the relationships among codes, which are highlighted with an axial link or link [22-32].

\section{Trustworthiness of the Study}

Findings were discussed between the researcher and the participants. Accuracy was maintained throughout the study by making use of member checks and allowing the participants who provided the information to check both the data and the interpretation.

\section{Dependability}

The researcher enhanced the dependability of this study by involving an expert in qualitative research to assist with data analysis and the interpretation of data. The researcher kept all records of all 
stages of the research process for the purpose of audits done by experts $[22,23,25,30,31]$.

\section{Transferability}

The researcher enhanced transferability by providing an in-depth discussion and interpretation of data and by using focus group discussions $[22,23,25,30,31]$.

\section{Conformability}

The researcher maintained the confirmability of this study by taking comprehensive notes throughout the research. The researcher also ensured that data is accurately interpreted, and reflected the information that was obtained from the participants. Thus the findings were shared with participants to confirm the information they gave. Information was discussed with the supervisor and the qualitative research expert to prevent any form of bias $[22,23,25,30,31]$.

\section{Results and Discussion}

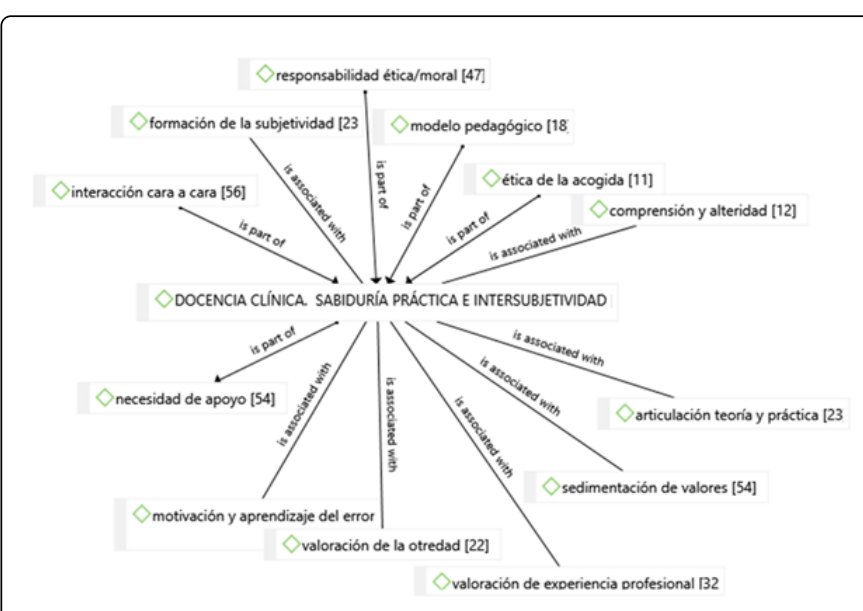

Figure 1: Network 1.

The meanings unveiled by nurses who perform clinical teaching in public hospitals in southern Chile allow us to understand the complex intersubjective relationships that are constructed, from the conceptual to the emotional areas, considering the professional path and the personal experience around the teaching. The social reality of this everyday life world is marked by discursive interaction with others (Figure 1).

Through the investigative process and the methodology used, not only are the meanings of intersubjective relationships revealed, but the different hospital contexts show the concrete setting in which teacher assistance integration is developed from the point of view of practical wisdom.

Based on the reports of nursing professionals, relevant aspects to consider are revealed, mainly in the definition of the value they give to the subjective and intersubjective dimension and to the pedagogical tools that are necessary to carry out this task consciously.

In relation to the concept of clinical teaching in nursing, several names associated with this construct arise, such as clinical tutor and guide nurse; the latter being the most recognized figure by the interviewees, since in some cases, the word "educator" is associated with a professional who is dedicated to the teaching in the classroom. Through the narratives, there is a lack of clarity regarding the categorical denomination of the nursing professional who guides students in their practical experiences. This could without any doubt generate ambiguities in the functions to be performed, as well as with the scarce recognition or valuation of the role.

One of the meanings that stand out is the idea of "professional model." The nurses remember the educators who were exemplary mentors in their initial professional training and recognize the importance of being a good model for students, worthy of imitation, the one that shows the best of himself/herself, so that students can reflect in them and visualize their own future. The role of model is one of the most far-reaching means to transmit values, attitudes and patterns of thoughts and behaviors to students, since the testimony leaves unintelligible traces in the formation of the human being [33]. Based on the above, the idea that the main strategy that all clinical educators can show is their own example is reinforced, since this modeling constitutes an important training reference for students. Assuming this idea in a responsible way, allows replicating those educator practices that over time will improve the quality of the profession as a whole.

Regarding the "pedagogical model" code to Freire [19] "who forms is formed and reforms when forming and who is formed is formed when formed"; therefore, subjects are not reduced to the category of objects. This is relevant for the training processes as it challenges the teaching management and it requires a personal and professional profile that allows the student an integral accompaniment. In order to fulfill this task, it is essential that teachers understand the value that the pedagogical knowledge of content has and the teacher empathy with his students.

Regarding the "need for support" code, teaching is defined as the teacher's effort to help students process information meaningfully and become students who self-regulate their learning; one of the methods that forms this new paradigm is the scaffolding [34]. As it has been seen, the support is a relevant axis for those who start in the profession. Because of this, the most experienced teacher tutorials, to those who are beginners, are important; this mobilizes, especially to those who help, a high sense of vocation, and personal and professional modeling.

For the "theory/practice articulation" code, it is important to note that integration is a consequence of the student's dialogical relationship with the world [35]. One of the most complex challenges of the formative act is the achievement of full agreement between theory and practice, because through real examples students visualize the complexities involved in putting into practice what has been theoretically learned in classrooms. This situation invigorates the formative processes, since it implies an enriching relationship between the empirical evidence accumulated through the scientific and formal knowledge and the wisdom that the practice itself grants through the intersubjectivity experience.

Regarding the "sedimentation of values" code, the clinical educator acts as a tutor and must be characterized by his/her accessibility and closeness at any stage of the formative period, by his/her role of facilitator and director of the learning process that corresponds to him/ her. $\mathrm{He} /$ she must be a person who not only has a well-organized mind, but also that the simple lines of his/her spirit indicate to the student that he/she is before a good person [35]. A fundamental aspect in higher education is the teaching of values; this implies that educators must have the ability to understand that not only must technical and 
Page 5 of 6

instrumental skills be developed, but also aspects related to mood/ spirit and willingness to accompany the students are essential components in students' mentoring.

In the "face-to-face code interaction", the professional commitment or vocation evidences the idea that the learning is always first intersubjective or interpsychological and then intrapsychological. In other words, firstly, it is everybody's task and finally, it is one's task, since the conditions resulting from optimal and fluid intersubjective relations affect the proper appropriation of the learners' knowledge.

Related to the "motivation and learning by mistake" code, the action of the clinical mentor educator is understood as the off-line counseling from one person to another for the realization of a meaningful transition of knowledge, work or thought [36]. One of the most significant roles in the teaching-learning process is to assume the task of guidance and orientation for beginner professionals and students who are in the final formative phase. The presence of a good guide safeguards the support that every student needs when he/she has made an inadequate decision or does not have the practical tools to carry out a particular action. The welcome word, to value learning by mistake, can be important for a student in training.

Regarding the "valuation of professional experience", it is interesting to note that students generally wish to work with clinical educators who have experience and competencies in their specialty and who have knowledge to provide quality care [37]. Finally, regarding "ethicalmoral responsibility", it should be emphasized that teaching is a moral task because it is an action that is carried out with other human beings, where questions concerning what is fair, righteous and virtuous are always present. This implies that the educator's behavior, at all times and in all senses, is a moral issue.

\section{Conclusion}

Today one of the axes of the paradigm shift in the health professionals' behavior is linked to the need to move towards a more humanizing attention to patients. This implies that both clinical educators and students must start from the base that the most important value that a person has is precisely to be a person; therefore, the moral commitment to him/her is the basic condition of every human relationship, which will always be intersubjective.

This research shows the need for pedagogical training to clinical educators. Pedagogical-didactic tools are required since the intuitive and based on past experiences are not necessarily related to current methodologies, which hinder the development of appropriate and relevant didactic transpositions of the disciplinary contents that students should know and know how to do.

Intersubjective relationships in nursing are fundamental for the theoretical-practical integration, especially in the final training period; therefore, understanding the nurses' experience in the educational process must be a permanent concern of the educational institutions in order to devise strategies which will improve the teaching-learning settings and the teaching quality.

\section{Conflict of Interest}

The authors declare that there is no conflict of interest.

\section{References}

1. Serrano P, Martínez M (2008) The tutoring of clinical practices in undergraduate nursing. Rev Nurs Goals 21: 28-32.

2. Brevis I, Sanhueza O (2008) Nursing teaching integration in nursing: Problems in its construction. Rev Elec Enf 10: 367-73.

3. Latrach C, Soto P, Gonzalez I, Cabellero E, Inalaf C (2009) Quality assurance in the training of nurses from the perspective of national accreditation processes. Rev Sci Nurs 15: 79-94.

4. MINSAL (2007) General Administrative Standard No. 19, Management of Nursing Care for Closed Care. Chile's government. Ministry of Health.

5. Mansilla, JG, Ricouz A (2016) Experience of the clinical teaching role of hospital nurses in southern Chile. Rev Sci Nurs 22: 101-111.

6. Andrews G, Brodie D, Andrews J, Hillan E, Thomas B, et al. (2006) Professional roles and communications in clinical placements: A qualitative study of nursing students perceptions and some models for practice. Int J Nurs Stud 43: 861-74.

7. Rocha SM, de Almeida MC (2000) The process of nursing work in collective health and interdisciplinary studies. Rev Lat Am Enfermagem 8: 96-101.

8. Galicia L, Rodríguez S, Cárdenas M (2010) The process of integrating the student into the clinical environment for reflective learning. Rev Nursing University ENEO-UNAM 7: 53-61.

9. Herskovic P (2009) The pedagogical training of clinical academics in the Faculty of Medicine of the University of Chile. Rev Hosp Clin Univ Chile 20: 315-318.

10. Illesca M, Cabezas M, Nuin C, Jürschik P (2010) Competences of clinical nurse teacher, University Lleida (Spain) and La Frontera (Chile): student perception. Cieñe enferm 16: 99-106.

11. Marriner A, Raile M (2007) Models and theories in nursing. Elsevier, Barcelona.

12. Servicio de Salud Valdivia (2012) Valdivia Base Hospital. Manual of Organization Valdivia Base Hospital. Valdivia, Chile: Valdivia Health Service.

13. Marriner A, Raile M (2007) Models and theories in nursing. Elsevier, Barcelona.

14. Ayres JRCM (2007) A hermeneutic conception of health. Physis: Rev Saúde Coletiva 17: 43-6.

15. Ayres JRCM (2008) To understand the practical meaning of health actions: Contributions of philosophical hermeneutics. Rev Collective Salt 4: 159-172.

16. Agramonte A, Farres R (2010) Influence of care management on the quality of health care. Rev Cubana Enfermer 26: 14-26.

17. Pellón M, Mansilla J, San Martín D (2010) Importance of practical didactic wisdom as a source of knowledge base for the teaching of Anatomy. Int J Morphol 28: 219-226.

18. Freire $P$ (2006) Importance of practical didactic wisdom as a source of knowledge base for the teaching of Anatomy.

19. Cook M, Alvarez E (2009) Characteristics of the nursing clinical teacher. Horiz Enferm 20: 53-61.

20. Dahlberg K (1996) Intersubjective meeting in holistic caring: a swedish perspective. Nurs Sci Q 9: 147-151.

21. Flick U (2012) Introduction to qualitative research. Morata, Madrid.

22. Gadamer HG (1993) Truth and method. Follow me, Salamanca.

23. Bisquerra R (2004) Methodology of educational research. The Wall, Madrid.

24. Mafumo JL, Netshandama VO, Netshikweta L (2017) Clinical supervision as an integral part in training for bridging course learners at selected hospitals of Vhembe district, Limpopo province, South Africa. J Nurs Care 6: 392.

25. Brink H, Van Der Walt C, Van Rensburg G (2008) Fundamentals of research methodology for health care professionals. Juta and Company, Cape Town. 
Citation: Sepúlveda JM, Moya AR, Billeke CH (2017) Clinical Teaching of Nurses in Southern Chile Hospitals: Practical Wisdom and Intersubjectivity. J Nurs Care 6: 426. doi:10.4172/2167-1168.1000426

Page 6 of 6

26. Jooste K (2009) Supervision in social work. Columbia University Press, New York.

27. Botma Y, Greef M, Mulaudzi FM, Wright SCD (2010) Research in health sciences. Heinemann, Cape Town.

28. Strauss A, Corbin J (2002) Bases of qualitative research. Techniques and procedures to develop grounded theory. Editorial University of Antioquia, Medellín.

29. Burns K, Grove S (2011) The practice of nursing research: Conduct, critique and utilization. St Louis, Saunders, Missouri.

30. Polit DF, Beck CT (2008) Nursing research: Generating and assessing evidence for nursing practise. Philadelphia Lippincott.

31. Huaiquián CA, Mansilla JG, Lasalle, V (2016) Attachment: representations of nursery educators in kindergartens in Temuco, Chile. Rev Lat de Cie Soc Child Youth 14: 1119-1129.
32. Perrenoud P (2004) Ten new skills to teach. Graó, Barcelona.

33. Beltrán J, Bueno J (1995) Psychology of the education. Barcelona: Alianza, Barcelona.

34. Brandom R (2002) The articulation of the reasons. An Introduction to Inferentialism. Siglo XXI, Madrid.

35. Mansilla J (2008) Ordo amoris: Phenomenology of love in Max Scheler, order and disorder of the human heart. Rev Cusho 2: 73-90.

36. Schõn D (1987) Educating the reflective practitioner: Toward a new design for teaching and learning in the professions. Jossey-Bass Publishers, San Francisco.

37. Villa A, Poblete M (2007) Competence-based learning, A proposal for the evaluation of generic competences, Customer Service Representative. 